\title{
Letter from the President
}

Dear Readers,

On behalf of the editorial board of the Columbia Undergraduate Science Journal, I am proud to present the 15th edition of our undergraduate publication. Over the past fifteen years we have published a wide-variety of work produced by undergraduate student-scientists. From our first edition, which featured innovative work on cell-cell communication in bone degeneration, to our present edition, which includes novel insights on the gut microbiome's contribution to epithelial barrier permeability, it is evident not only that science has made leaps, but that our young scientists have as well. As the countable infinity of scientific knowledge left to learn grows ever smaller, I am amazed by the remarkable curiosity of undergraduate student-scientists, who tackle seemingly insurmountable questions with vigor and drive.

The entire CUSJ enterprise has taken great strides over the past fifteen years. As one of the first undergraduate peer-reviewed scientific journals, we paved the way many years ago for the creation of scientific publications at other universities. Now, on our 15th anniversary, CUSJ spearheaded the formation of and currently leads the National Undergraduate Consortium of Science Journals, uniting more than 20 undergraduate scientific publications in an effort to ensure high ethical standards. At our now-annual National Undergraduate Conference on Scientific Journalism, we gathered more than 500 students from 34 countries to visualize the way forward for young scientists. As we move into the next fifteen years of CUSJ, I look forward to the continued sharing of scientific pursuits and common values.

I would like to thank all students who submitted to CUSJ, past and present. It is your commitment to thoughtful experimentation and thorough questioning that drives the young scientific world. I would like to specifically commend the authors published in our 15th edition, who have demonstrated an admirable commitment to scientific achievement and collaboration in this unusual time. I am grateful to you, your research mentors, your parents, and all who supported you for making CUSJ possible.

It has been a great honor to serve as the President and Chief Editorial Officer of the Columbia Undergraduate Science Journal for the 2020-2021 academic year. Thank you to the editorial team, our selected peer reviewers, and our esteemed Faculty Advisory Board for ensuring the growth and prosperity of the young scientific community. Congratulations to all authors, and thank you to our readers!

Arya Rao

President, Chief Editorial Officer

Columbia Undergraduate Science Journal 